\title{
OFF THE GRID \\ LA FRAGMENTACIÓN COMO ESTRATEGIA EN TERRITORIOS DE TRANSICIÓN
}

\author{
Giovany Albarracin Vélez \\ Universidad Politécnica de Catalunya \\ Director: Julian Galindo \\ Carles Crosas \\ galbarracinv@ucacue.edu.ec
}

\begin{abstract}
RESUMEN
El acelerado crecimiento urbano en América Latina es un fenómeno que aunque asumido de manera general, requiere consideración del contexto y de alcance local; la cumbre mundial HABITAT III establece en sus Issue Papers que, dada la tendencia global de crecimiento de las áreas urbanas, estas tenderán a capitalizar de forma desigual la mayoría de recursos y ello puede tener efectos adversos en el acceso universal a los mismos. Esto hace pensar que el modelo de planificación centralizado, posicionado desde el ámbito académico y político, que apuesta por un crecimiento compacto en el que se insiste en la dicotomía entre campo y ciudad, es un modelo en crisis. Por lo tanto, es necesario replantearse conceptos como límite urbano y pensar en un cambio de paradigma que de paso a una nueva visión de planificación territorial más equitativa y respetuosa con el medio ambiente, capaz de garantizar el acceso de la población a los recursos básicos en entornos urbanos. Por tal motivo, este trabajo ubica su objeto de estudio en el borde entre campo y ciudad y lo conceptualiza como un tercer espacio, con características ecotonales, lugar de conflicto y de oportunidad, y explora escenarios autosuficientes desconectados de la red basados en la producción descentralizada y el consumo de los recursos in situ. La hipótesis de trabajo es que la experimentación de un sistema de producción y tratamiento de aguas fuera de red, desconectado, fragmentado, puede ser la estrategia más adecuada para fortalecer el carácter productivo de un sistema de espacios abiertos agrícolas, fomentando economías periurbanas y fortaleciendo el papel de estas áreas en el entorno urbano. Esta investigación desarrolla su discurso en base a tres imágenes simbólicas: Transición, Tercer espacio y Fragmentación, cada una de estas tres imágenes se discute a partir de algunos "objetos urbanísticos" concretos correspondientes a experiencias importantes de proyecto y planificación en el contexto global. La primera imagen evidencia la difícil transición de la ciudad de Cuenca, de un modelo de planificación racional comprensivo a otro cuyos contornos aún no están claros; la segunda fase intenta conceptualizar este espacio de transición a través de un tercer espacio caracterizado por la ambigüedad de usos y actividades, difuso, que no cumple funciones ni propiamente urbanas ni propiamente rurales, e intenta mediante un análisis multi escalar y con énfasis en la construcción hidroespacial evidenciar sus caracteres y problemas, para finalmente en una tercera fase mediante una exploración proyectual reconocer pautas, criterios y estrategias que permita cuestionar el planeamiento habitual y presenta nuevos caminos para entender e intervenir en estos procesos de transformación. Los resultados más importantes giran en torno a la definición de un sistema de infraestructuración hidráulico innovador, adecuado a los caracteres fragmentados del periurbano de Cuenca, que por un lado permite fortalecer la producción de alimentos a escala local, y por otro, el tratamiento de aguas mediante un proceso de fitoremediación, permite devolver las aguas limpias a los ríos y a la vez estos pueden funcionar como espacios públicos.
\end{abstract}




\section{1.- INTRODUCCIÓN}

Un campesino labra la tierra, es época de siembra. Dos mujeres caminan montaña arriba hacia su pequeña parcela que les permite, mediante la siembra de hortalizas contribuir en el sostenimiento de su hogar; otra mujer se cruza en el trayecto en busca de pasto para sus animales. Estas imágenes no tendrían nada de especiales si no sabríamos que este territorio en los próximos años sufrirá una fuerte transformación y quizás lo relatado solo quede en la memoria de personas mayores.

El inicio del siglo XXI será recordado como el momento en el cual la población mundial vive mas en ciudades que en el campo (Amado \& Poggi, 2014). La ciudad intermedia de Cuenca - Ecuador ejemplifica este escenario en el que ya el $65 \%$ de la población es urbana. Este fenómeno plantea una "nueva cuestión urbana" caracterizada por desigualdades e injusticia espacial junto con claras consecuencias ambientales (Secchi, 2013). En el Ecuador se intenta un cambio de paradigma de crecimiento urbano, contemplado dentro del "Plan Nacional del Buen Vivir" específicamente en el objetivo 3 se argumenta : Mejorar la calidad de vida de la población (3:10.- Garantizar el acceso universal, permanente, sostenible y con calidad a agua segura y a servicios básicos de saneamiento, con pertinencia territorial, ambiental, social y cultural (SENPLADES, 2013). Dicho planeamiento, requiere por lo tanto, una profunda revisión de los mecanismos e instrumentos con los cuales se ha venido ordenando el territorio.

Por otro lado en la cumbre mundial HABITAT III que se celebró en octubre de 2016 en la ciudad de QuitoEcuador establece en sus Issue Papers que "dada la tendencia global de crecimiento de las áreas urbanas, estas tenderán a capitalizar de forma desigual la mayoría de recursos y ello puede tener efectos adversos en el acceso universal a los mismos" (UN-HABIT, 2015), por lo tanto se hace necesario explorar nuevas herramientas acorde a la problemática actual que permita ver y gestionar los recursos fuera de visiones convencionalmente asumidas por los llamados territorios urbanos.

El objetivo del estudio es reconocer criterios y estrategias de actuación para los procesos de transformación, en beneficio de un equilibrio entre lo rural y lo urbano a través de un espacio de transición que lo llamaremos "tercer espacio"; se trata de un proyecto de marcado impacto social y económico; más allá de la justificación y oportunidad científica del proyecto, su temática y objetivos se alinean con las necesidades sociales y económicas del contexto territorial en la que se despliega la investigación. En el caso de Ecuador, los objetivos y ejes prioritarios para el desarrollo económico, social y ambientalmente sostenibles están definidos en el Plan Nacional del Buen Vivir, el documento matriz redactado por la Secretaria Nacional de Planificación que programa y prioriza las acciones e inversiones a nivel estatal (http://www.buenvivir.gob.ec). La presente propuesta de investigación entronca claramente con los objetivos establecidos por el Plan Nacional del Buen Vivir y, más concretamente con los objetivos de igualdad y equidad territorial (Objetivo 2) así como a la promoción de la sostenibilidad ambiental territorial (Objetivo 7). Además se pretende que esta investigación sea un punto de partida para discutir no solo la habitabilidad de los asentamientos humanos sino también la oportunidad de plantearlos con relaciones armónicas con los recursos naturales y un fortalecimiento del papel de las áreas rurales en el entorno urbano.

La hipótesis de trabajo es que la experimentación de un sistema de tratamiento de aguas fuera de red, desconectado, fragmentado, puede ser la estrategia mas adecuada para fortalecer el carácter productivo de un sistema de espacios abiertos agrícolas, fomentando economías rurales para fortalecer el papel de las áreas rurales en el entorno urbano.

La ciudad de Cuenca, como muchas de las ciudades de Latinoamérica, experimentan un proceso de transformación en su territorio de carácter expansivo, tipo "mancha de aceite" (Muñiz \& García, 2006), que se expresa principalmente en los territorios de transición entre la ciudad y el campo, conformada por fragmentos rurales, urbanizados y elementos naturales; por lo tanto, entender estas zonas de borde, para explorar estrategias de diseño que permitan por un lado satisfacer esta demanda de crecimiento y por otro mantener el equilibrio entre elementos naturales y agrícolas, son el objetivo del presente estudio.

\section{2.- METODOLOGÍA}

El presente trabajo de investigación ha empleado el mapeo interpretativo para analizar el estudio de caso en base a tres imágenes simbólicas: Transición, Tercer espacio y Fragmentación. La primera imagen 
evidencia la difícil transición de la ciudad de Cuenca, de un modelo de planificación racional comprensivo a otro cuyos contornos aún no están claros; la segunda fase intenta conceptualizar este espacio de transición a través de un "tercer espacio" caracterizado por la ambigüedad de usos y actividades, difuso, que no cumple funciones ni propiamente urbanas ni propiamente rurales; se propone, por medio de un análisis multiescalar y a través de constatar una construcción hidroespacial evidenciar sus caracteres y problemas. Finalmente en el tercer apartado mediante una exploración proyectual reconocer criterios y estrategias que permita cuestionar el planeamiento convencional y proponer estrategias innovadoras en el manejo del agua. A manera de conclusión se presenta nuevos caminos para entender e intervenir en estos procesos de transformación.

Como caso de análisis se ha considerado la parroquia Baños de la ciudad de Cuenca - Ecuador (la ciudad de Cuenca tiene 15 parroquias rurales). La ciudad ecuatoriana de Cuenca reúne las características idóneas para el estudio planteado. Por un lado, se trata de una ciudad intermedia que ejemplifica el escenario en el que reside el $65 \%$ de la población urbana, y además el que será previsiblemente, el tipo de entorno de la mayoría de crecimiento urbano global (Ballet, C. Llop, 2004). En segundo lugar, las proyecciones para los próximos treinta años convierten a Cuenca en una de las ciudades con una tasa de crecimiento urbano más acelerado de toda Latinoamérica (Banco Interamericano de Desarrollo, 2014), siendo por ello el caso de estudio (parroquia Baños) de especial relevancia para el objetivo del proyecto, ya que presenta uno de los índices de crecimiento mas altos de la ciudad.

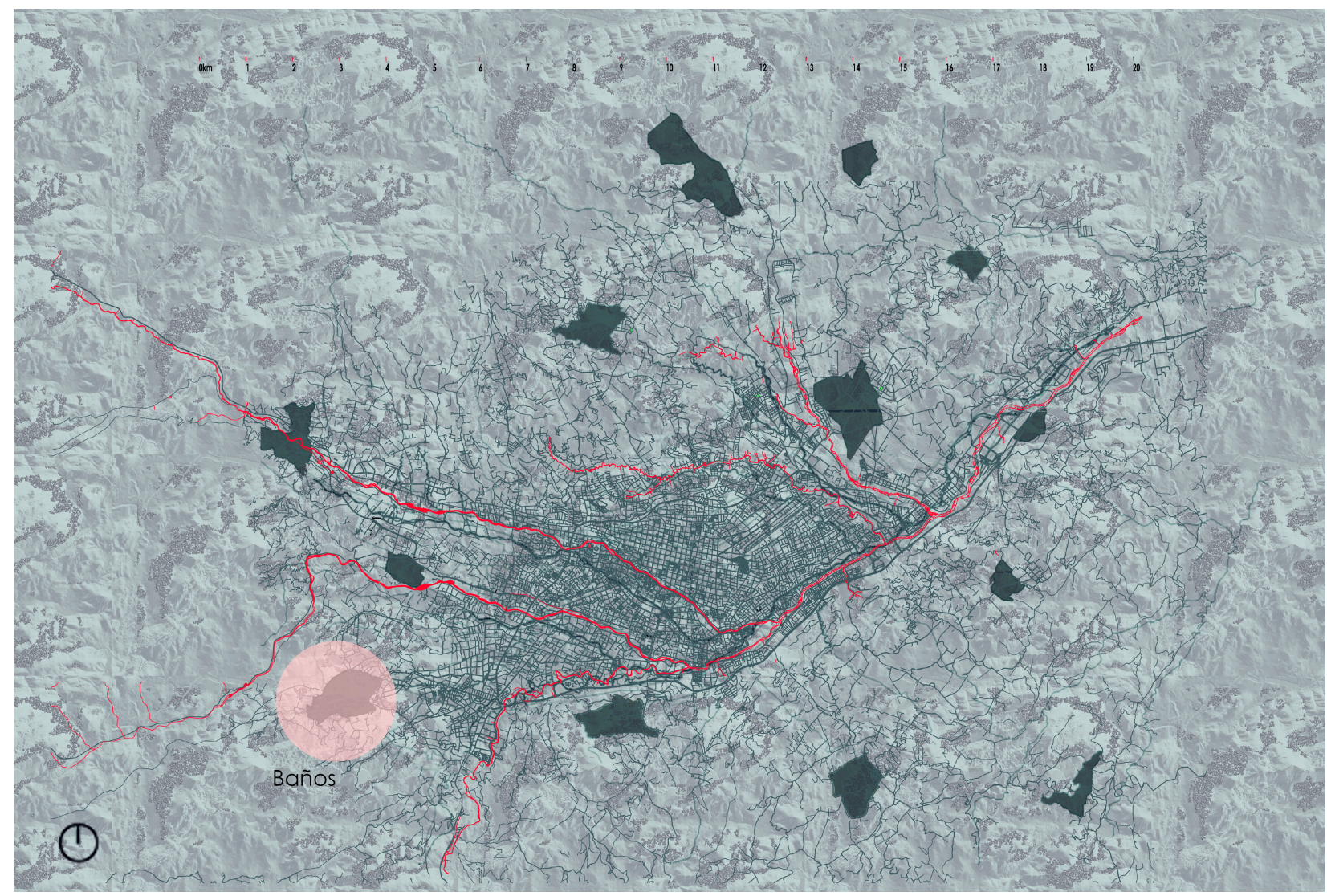

Fig. 1 Parroquia Baños, elaboración propia.

\subsection{Transición}

Si observamos la ciudad de Cuenca - Ecuador a través de su primer plan de ordenamiento, mediados del siglo pasado y su último plan realizado en los primeros años del siglo XXI, se reconocen dos corrientes en la forma de entender la ciudad, la primera una corriente de matriz moderna, muy clara y cobijada por las instituciones políticas mas importantes y por la academia. Tres lugares o dispositivos indisociables afectan la producción del espacio público y en un sentido más amplio la ciudad y el territorio, según Derrida. El autor describe en su libro "Los Espectros de Marx", que el primer dispositivo es el discurso oficial de la cultura política, donde prevalecen los modelos occidentales; el segundo dispositivo es la 
cultura mas mediática que con producciones selectivas, jerarquizadas de información afectan la producción de la ciudad y el territorio; y la última cultura es la erudita o académica, con un discurso a favor de la edición académica, comercial y mediática. Éstas tres culturas discursivas (política, mediática y académica) están soldadas por los mismos aparatos o por aparatos indisociables; dichos aparatos complejos, diferenciales, conflictivos, sobredeterminados se comunican, se recurren constantemente entre ellos para garantizar la hegemonía, es decir el discurso dominante, esta ha sido la responsable de ordenar la ciudad y el territorio en estas últimas décadas. Sin embargo, una segunda corriente a emergido sobre el territorio de manera difusa, poco comprensible que la denominaremos posmoderna, estas dos corrientes pertenecen a un mismo río, el de la transformación de la ciudad y el territorio. Por lo tanto se vislumbra como necesario, dadas las condiciones ya esbozadas por la ciudad, una difícil transición de la ciudad moderna hacia una posmoderna.

La primera narración, un modelo de planificación racional comprensivo, omnicomprensivo y totalizador parte de una visión sinóptica que va desde un programa general hasta los proyectos ejecutivos, cuyo objetivo principal es GUIAR y CONTROLAR el uso del suelo, a través de prohibiciones, normas y reglamentos (Secchi, 2000); ocho planes de ordenamiento dan cuenta de ello, el primero en 1942 y el último en 2015.

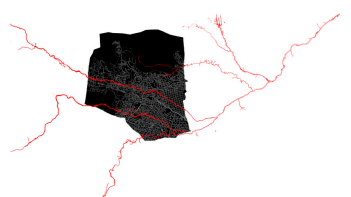

$1942(1035,691 \mathrm{ha})$

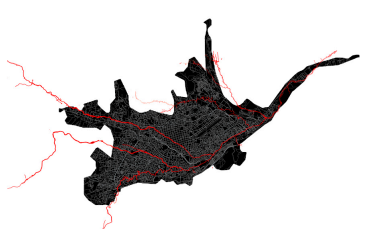

1966 (6971,106ha)

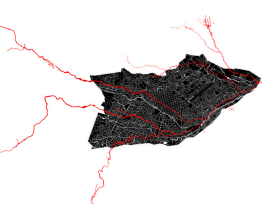

$1947(2147,100 \mathrm{ha})$

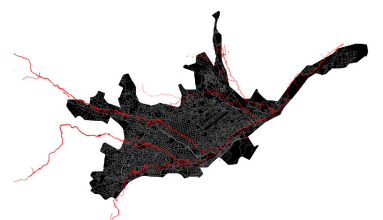

$2002(7299,688 h a)$

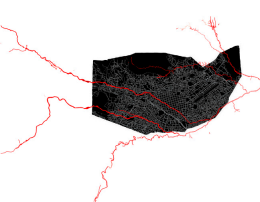

1971 (3251,126ha)

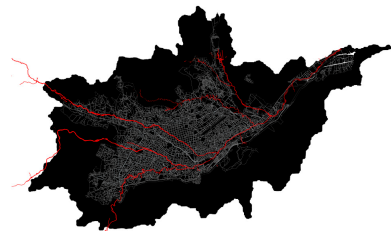

2011 ÁREA URBANA(7299.688ha) PERIURBANO (11378,374ha)

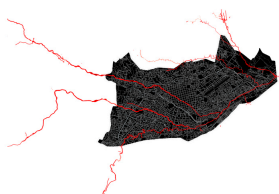

$1982(4174,349 \mathrm{ha})$

Fig. 2 Planes de ordenamiento de la ciudad de Cuenca, elaboración propia.

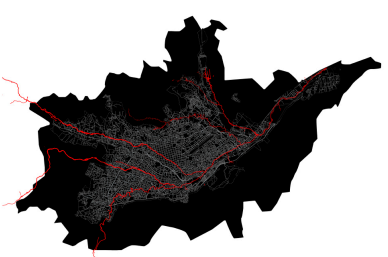

2015 ÀREA URBANA(7171,787ha) PERIURBANO (1 1576, 187ha)

En este trayecto cronológico, lineal ordenado, se pretende básicamente, organizar la ciudad en función de la densidad de la población, para lo cual, la ciudad se codificó con eficacia y la práctica de la zonificación construyó una ciudad homogénea, mesurable y comprensible con valores posicionales claramente identificados, es decir, en el centro actividades direccionales y comerciales de mayor prestigio, las grandes instituciones y las residencias de los grupos mas acomodados; gradualmente hacia las afueras actividades menos especializadas y vivienda de los grupos sociales menos pudientes, por tanto, la pirámide de los valores posicionales y estéticos era espejo de la pirámide social (Secchi, 2000).

La segunda narración cuya declinación es posmoderna, la ciudad sufre una transformación radical, y se reconoce el carácter incierto propio de un sistema complejo, cuyas características principales son la fragmentación, heterogeneidad y dispersión, por tanto, se evidencia el fenómeno denominado "nueva cuestión urbana" argumentada por Bernardo Secchi.

En el caso de la ciudad de Cuenca, es posible reconocer una imagen nítida de lo que usualmente se considera como zona urbana, cuyo proceso de expansión se ha dado a la luz de varios planes de ordenamiento, ocho en total (1942 - 2015) .Sin embargo, es posible advertir que está en marcha un proceso paralelo a este, no tan claro, difuso, además no muy considerado en el discurso hegemónico, y que sus expresiones, principalmente se dan por la tensión creada entre la ciudad central y la cabeceras parroquiales, articuladas por un viario principal claramente identificado. Esta nueva cuestión urbana se ubica en el borde de la llamada ciudad, entre lo rural y lo urbano y constituye un espacio de transición, un "Tercer espacio". (Ver figura 3) 


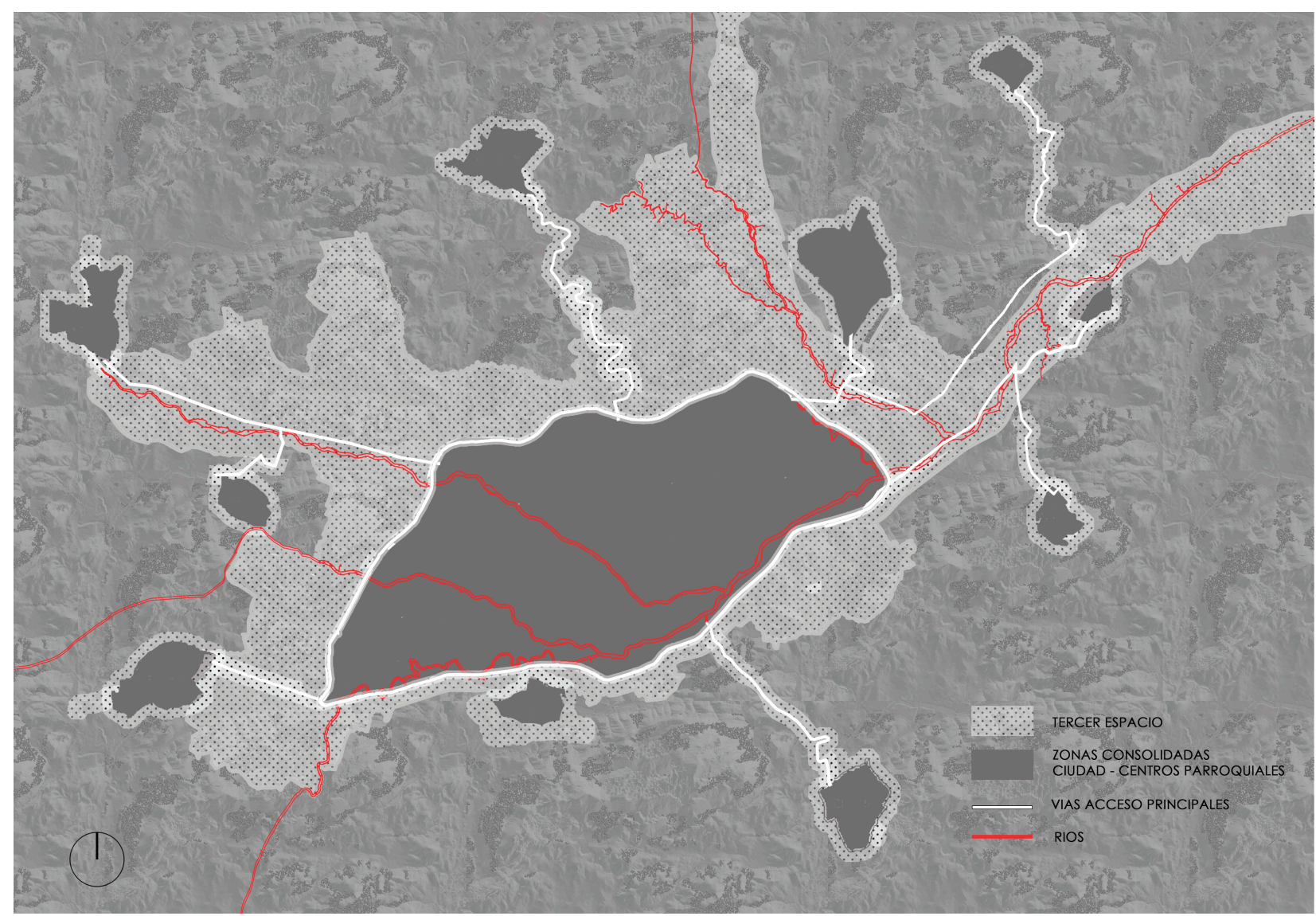

Fig. 3 Proceso de transformación, tensión entre la ciudad central y las cabeceras parroquiales, elaboración propia.

\subsection{Tercer espacio}

Entender la ciudad ha sido siempre uno de los elementos centrales en el urbanismo, pero sobre todo ahora se ha convertido en un aspecto fundamental. En la Cuenca contemporánea, dada la transición que argumentamos, es una tarea que está por hacerse. Pero para entenderla hace falta girar la mirada hacia un espacio cuya definición no es precisa, pero resulta fundamental en el proceso de transformación al que se ve avocada. Entender esta ciudad para eventualmente mejorarla exige necesariamente formular nuevos instrumentos, métodos de diseño y planificación urbana. Si la ciudad moderna contaba con herramientas lineales (análisis - proyecto) dada su condición de continuidad; la ciudad contemporánea exige nuevos mecanismos que intenten relacionar la complejidad, el caos, la confusión y sobre todo herramientas o estrategias que puedan estar a tono con el carácter fragmentado de los territorios contemporáneos.

Así entonces, la ciudad de Cuenca, no escapa a este nuevo fenómeno, una ciudad con claras muestras de fragmentación y dispersión, esta condición hace que los cambios sean una constante permanente, por consiguiente, tanto los métodos como las estrategias y normas que ordenaron la ciudad moderna exigen ser repensados. El presente apartado enfatiza la necesidad de entender este tercer espacio más allá de la dicotomía ciudad - campo y sobre todo superar las miradas dominantes desde la ciudad, sabiendo que esta no es una isla autosuficiente y que forma parte de un territorio, es mas no pudiera existir sin los innumerables intercambios que se producen, es decir, explorar un nuevo concepto, la Ciudad - Territorio. 


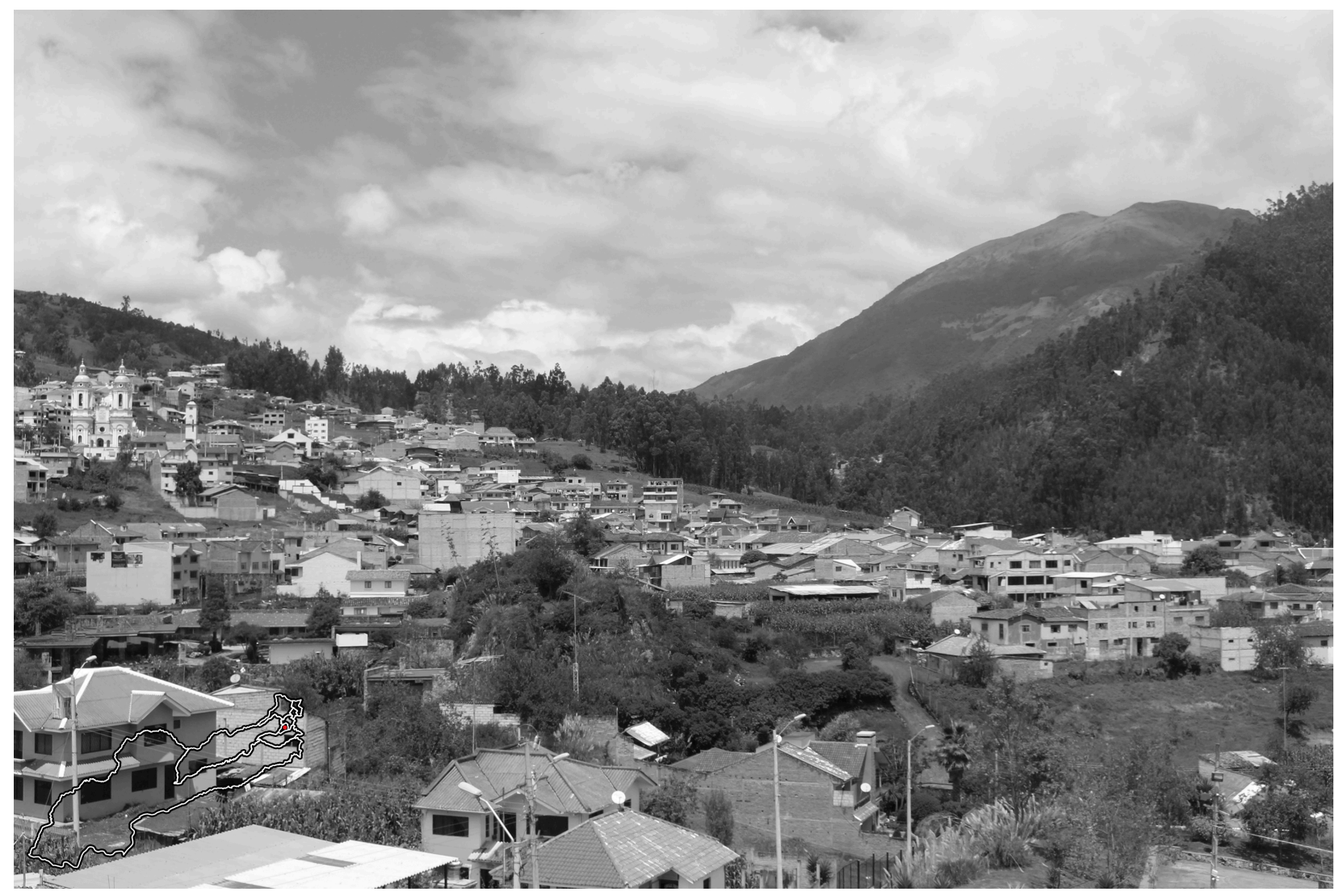

Fig. 4 Centro parroquial de Baños.

Pero como conceptualizar este espacio, que no cumple funciones ni propiamente urbanas ni propiamente rurales, y que se encuentra entre la ciudad y el campo contenido en un tercer espacio, un espacio de transición que esta asentado sobre los pliegues topográficos del territorio, y que en los últimos años ha recobrado interés, no porque este haya esclarecido y contribuido a superar la oposición entre lo rural y lo urbano, o porque haya un nuevo concepto de territorio, sino mas bien en virtud de la extensión de lo urbano al conjunto del territorio (Corboz \& Marot, 2001). Al igual que el territorio, este tercer espacio se remodela sin cesar, a una velocidad, que ha diferencia de la transformación lenta del territorio, su transformación se evidencia con mayor facilidad: se extiende, se relocaliza, se corre de lugar, se traslada, no es campo, ni es ciudad (Avila Sánchez, 2001). Este espacio tiene muchas similitudes con lo que en ecología se define como ecotono, que significa "ambiente en tensión". Este término indica aquellos hábitats que se colocan entre sistemas puestos en adherencia y que tienen un diferencial de alta diversidad, tales como el mar y la tierra o los prados y bosques, y que, aproximándose producen este "tercer espacio" (Burbano, Di Campli, Rodriguez, \& Solórzano, 2017). 


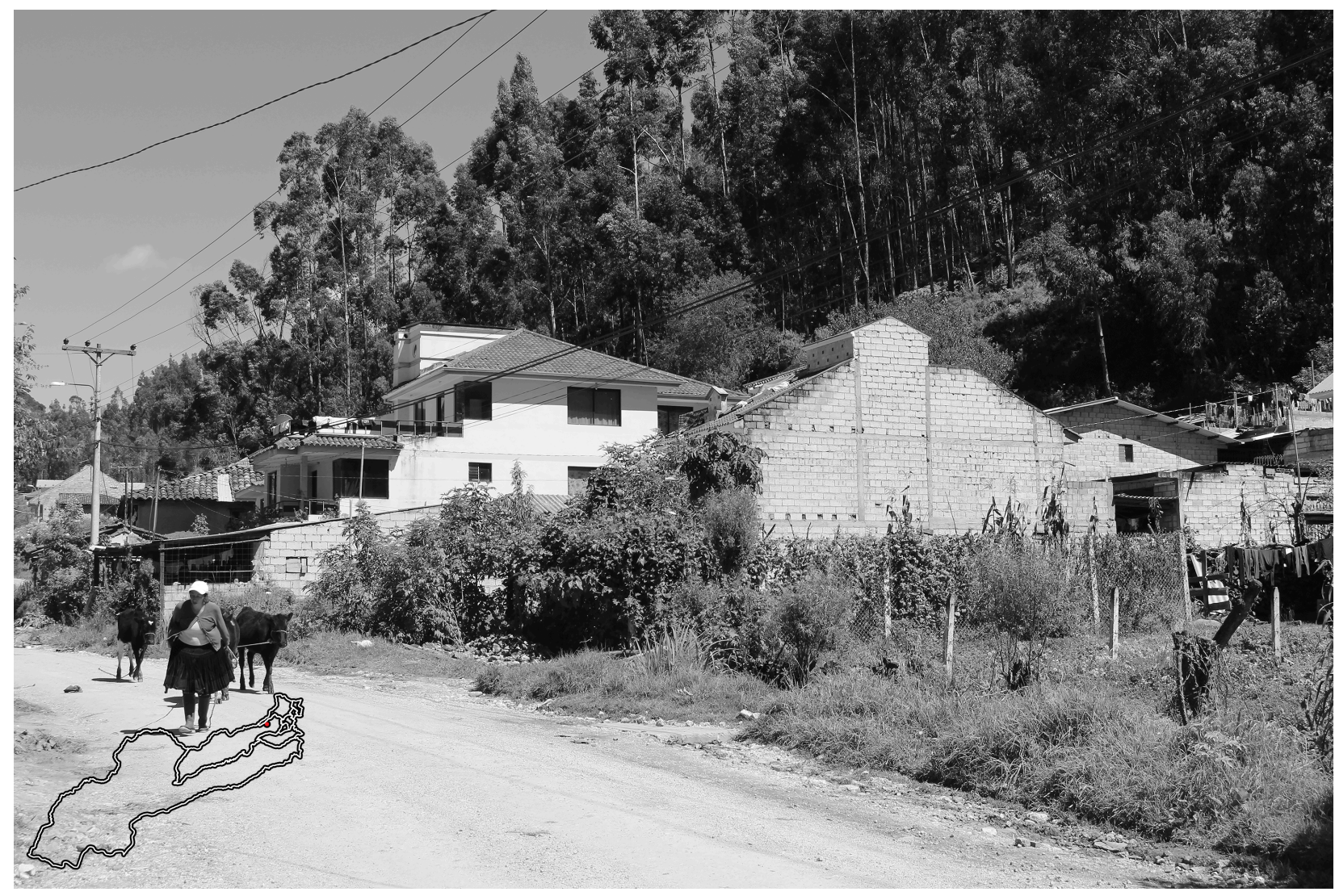

Fig. 5 Tercer espacio "ni campo ni ciudad", elaboración propia.

Este tercer espacio, para el caso de estudio, esta constituido básicamente por fragmentos rurales, urbanizados y naturales, articulados y delineados por el agua. El agua es una "cosa" indispensable par el mantenimiento del metabolismo, no solo de nuestros cuerpos humanos, sino también del tejido social más amplio (Swyngedouw, 2006a). Este elemento, recurso, permite observar e interpretar un proceso de construcción y transformación hidrosocial, que por su parte presenta una interrelación manifiesta entre: naturaleza, sociedad y tecnología (Boelens, Hoogesteger, Swyngedouw, Vos, \& Wester, 2016). Por lo tanto este apartado ha empleado el mapeo interpretativo para analizar el caso de estudio con un enfoque hidrosocial, con el fin de revelar las relaciones cambiantes entre los patrones de asentamientos, la infraestructura del agua y el paisaje.

La zona de estudio esta conformada por una basta área (22000 ha) emplazada en una marcada zona boscosa (plantaciones forestales y bosques nativos) que se encuentra a una altitud que va desde los 2580 a los 4200 m.s.n.m, asentada en las estribaciones de la cordillera del Cajas; gran parte de la parroquia es páramo, que sin duda es la característica mas importante de esta parroquia, estas áreas se destacan por su alto valor ecológico, ya que en ellas se condensa el vapor de agua que en forma de nubes, arrastrada por los vientos provenientes del Pacífico y del Atlántico, llegan a la parte mas elevada de la parroquia, generando agua que se condensa por las bajas temperaturas predominantes y es almacenada en la vegetación propia de la zona, vegetación que tiene la capacidad de retener agua y soltarla lentamente, alimentando los diferentes ríos y quebradas que nacen en esta área y que proveen a las fuentes de captación que dan de beber a la parroquia y parte de la ciudad de Cuenca. Cualquier intervención entonces debe estar bajo el precepto de su protección y mantenimiento. (Ver figura 6) 


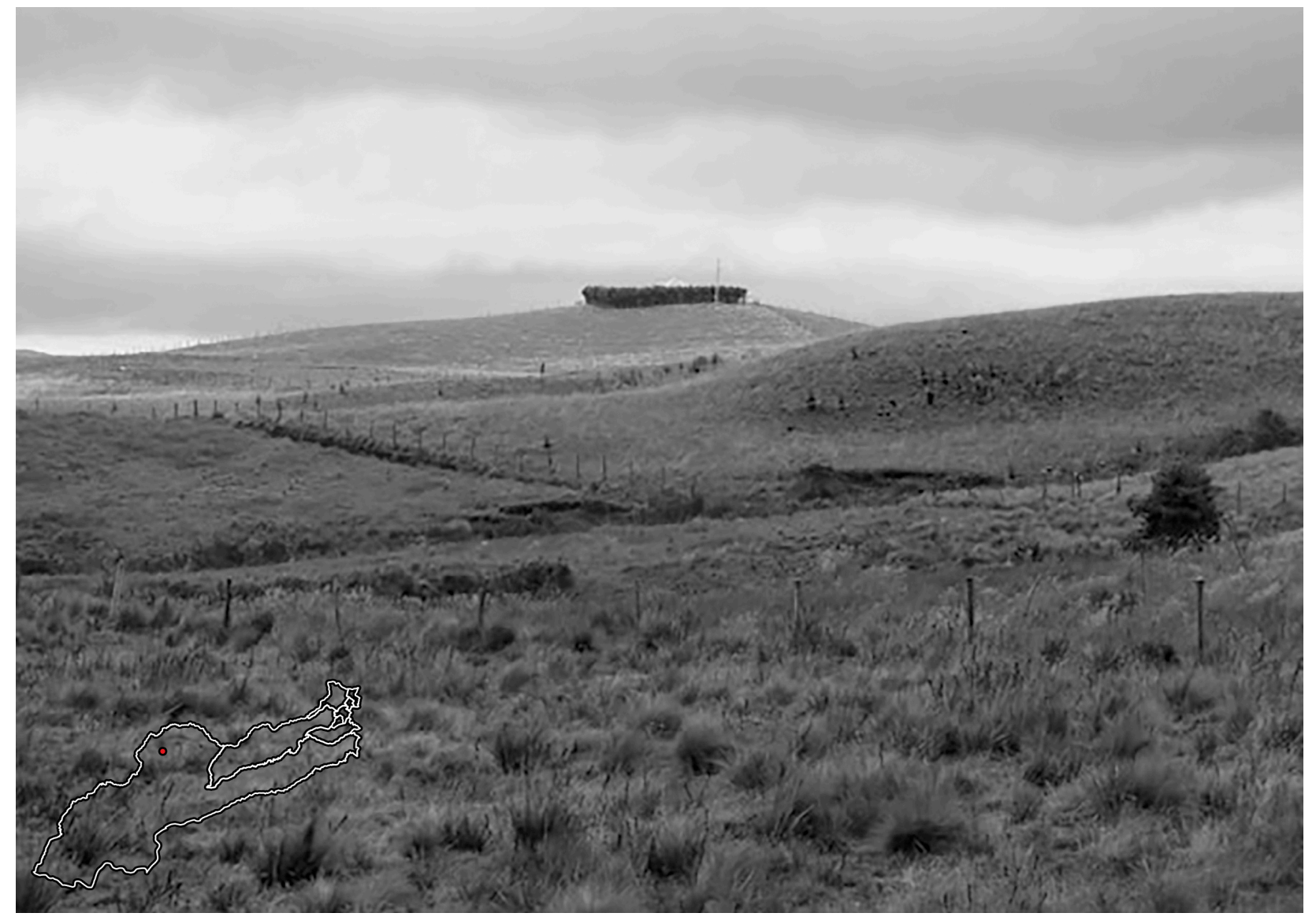

Fig. 6 Páramo, constituye el $90 \%$ de la parroquia, elaboración propia.

La parroquia Baños está conformada por 10 comunidades, cocida por una compleja estructura de viario de apariencia desilachada, con viviendas salpicadas en sus bordes que permiten una actividad agrícola de subsistencia, debido a los bajos niveles de productividad, baja tecnificación y limitada asistencia técnica, el territorio contiene una estructura minifundista de tenencia del suelo; sin embargo, existe una estructura hidrosocial que a permitido en gran medida sostener la economía de este territorio, esto se pone en evidencia al observar la comunidad Minas.

La comunidad de Minas está rodeada por montañas, lo que hace que gran parte de su suelo tenga pendientes pronunciadas, suelo y subsuelo predominantemente rocoso, las viviendas están ubicadas en distintos sectores pero principalmente a lo largo del canal que recoge el agua de riego que se alimenta del río Minas. Paralelo al recorrido hídrico, y con un viario principal conforman un filamento que estructura la comunidad, este tipo de infraestructuración le da un carácter agrícola a la comunidad que se complementa con el uso ganadero; los productos mas cultivados en la comunidad de Minas son de ciclo corto: papas, maíz y hortalizas que ha mas de satisfacer el consumo propio, generan un pequeño excedente que es comercializado en el mercado parroquial. Otra característica importante a ser considerada es que la comunidad esta asentada sobre la cota de la planta de tratamiento de agua, por lo tanto, esta comunidad no cuenta con agua potable, una paradoja sabiendo que su territorio es fuente de este recurso, por tal motivo su población (2000 habitantes aprox.) desarrolla su vida cotidiana a partir del agua entubada con todos los inconvenientes de salud que esto implica, y es posible afirmar que las enfermedades relacionadas con el agua son la principal causa de muertes prematuras en los países en desarrollo (Swyngedouw, 2006a). Esto, por un lado configura el territorio de la comunidad y por otro es su principal problema, el agua sin tratamiento, así como la inexistencia de un proceso o sistema de tratamiento de aguas residuales puede ser considerado un serio riesgo territorial. (Ver figura 7) 


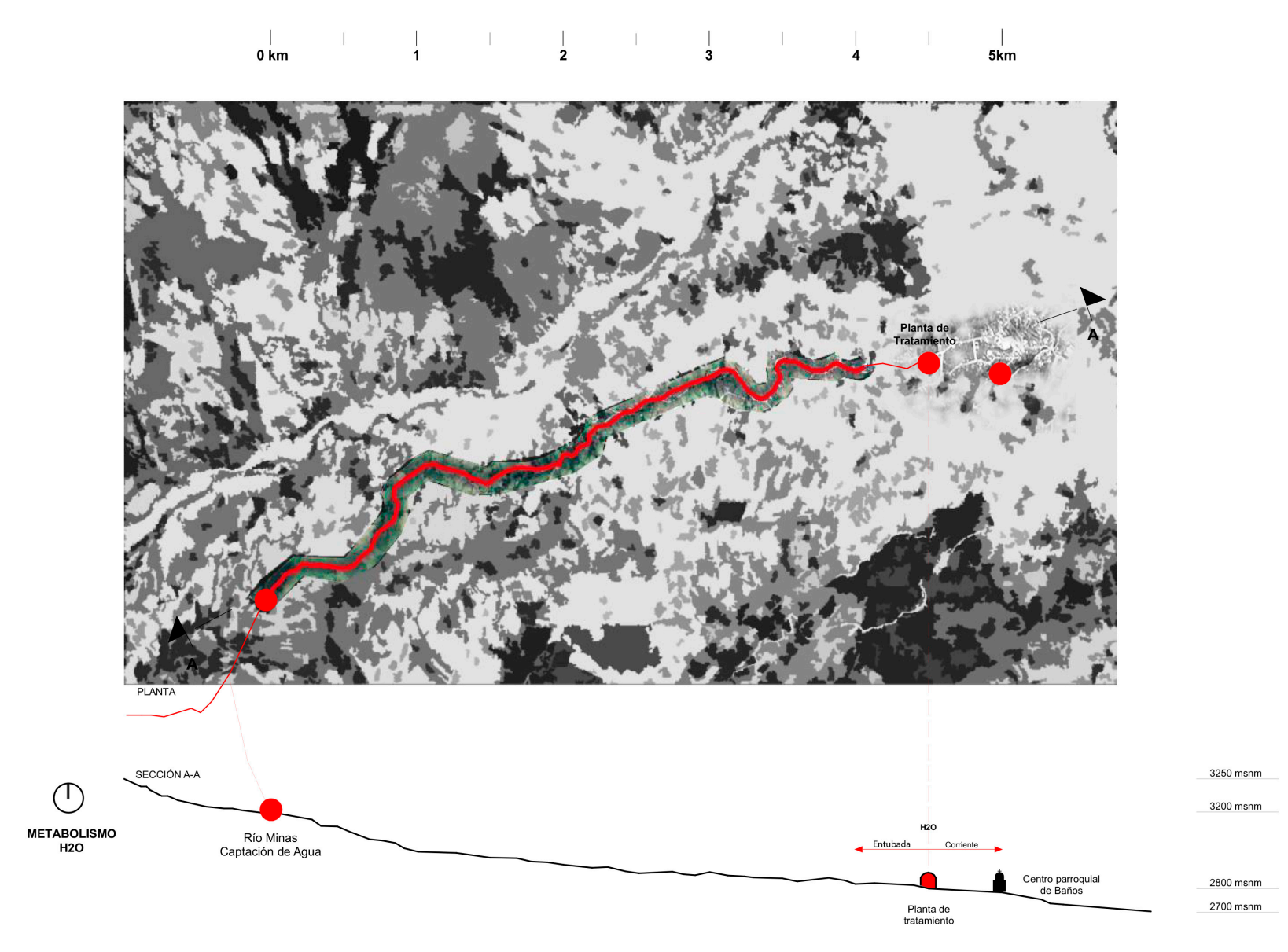

Fig. 7 Comunidad Minas, construcción hidrosocial (agua entubada), elaboración propia.

\subsection{Fragmentación}

"Off the grid" se inscribe en una investigación centrada en el crecimiento urbano ubicado en el interfaz entre campo y ciudad. Por otro lado, la justa y eficiente distribución de los recursos es uno de los grandes retos del creciente proceso de urbanización a nivel global, bajo ésta premisa la cumbre mundial HABITAT III que se celebró en octubre de 2016 establece en sus Issue Papers que:

"dada la tendencia global de crecimiento de las áreas urbanas, estas tenderán a capitalizar de forma desigual la mayoría de recursos y ello puede tener efectos adversos en el acceso universal a los mismos (...). Esta tendencia requiere estrategias de planificación urbana que promuevan una gestión descentralizada de los recursos en áreas tales como las energías renovables, el suministro de agua potable y el tratamiento de aguas residuales" (UN-HABIT, 2015).

Sobre descentralización, gestión distributiva y acceso universal a los servicios urbanos existe una copiosa literatura. Desde lecturas globales que confían en las posibilidades que ofrecen las nuevas tecnologías y las energías renovables (Rifkin, 2014), hasta el análisis cercano de casos concretos y específicos (Criqui, 2015). Observando detenidamente este rango de análisis, es posible inferir que los sistemas infraestructurales descentralizados van ganando peso como alternativa futura a los convencionales sistemas centralizados y acumulativos propios de la ciudad industrial y sus reproducciones contextualizadas. El papel que el trazado de las redes infraestructurales de servicios urbanos tienen en la planificación del acelerado crecimiento urbano a nivel global se apunta como pilar fundamental para un futuro urbano sostenible en el más amplio sentido. Desde el punto de vista de la sostenibilidad social, algunos autores defienden que los sistemas descentralizados son, con probabilidad, la estrategia más adecuada para proveer de condiciones básicas de habitabilidad y servicio a unas extensiones urbanas que, dada su velocidad de expansión, no pueden ser planificadas ni gestionadas según criterios de jerarquía vertical y acumulación centralizada de recursos, poniendo en evidencia las deficiencias de los sistemas centralizados como el caso de Lima y Delhi, frente al potencial de sistemas descentralizados 
(mini centrales) construidos, operados y manejados por la gente, en este caso por comités comunitarios (Criqui, 2015). Desde el punto de vista ambiental, cada vez son más los autores que abogan por un metabolismo territorial basado en la producción y consumo on-site y una contención del flujo de recursos. Finalmente, la sostenibilidad material y económica de los sistemas de infraestructuras dependen, también de factores como infraestructuras auto construidas con un mejoramiento progresivo y cuya gestión comunitaria se considera como el corazón de cualquier desarrollo local. (Choguill, 1999)

Dentro de dicho encaje conceptual, en construcción aún (Groh et al., 2015), hay algunas investigaciones que han analizado y documentado modelos descentralizados en la gestión y distribución del ciclo del agua y de los recursos energéticos. Pueden destacarse algunos estudios sobre el ciclo del agua, como el Plan de Agua para Poblados Jóvenes de Lima (Bonfiglio, 2002) y algunas otras experiencias sobre autosuficiencia energética en asentamientos urbanos de baja densidad (Ferrer-Martí et al., 2010) (Yadoo \& Cruickshank, 2012),como investigaciones más globales sobre autogestión de comunidades rurales (Rhoades, 2006). Por lo que refiere a entornos periurbanos sometidos a fuerte presión urbanizadora y de densificación, estos han sido objeto de diversas investigaciones desde el campo de las ciencias sociales (Silver, 2014). Sorprende, sin embargo, la escasez de estudios que hayan abordado esta cuestión desde un punto de vista morfológico-urbanístico con una aproximación holística que considere los flujos metabólicos en su conjunto, estudios que hayan analizado conjuntamente y con rigor modelos integrales de infraestructura en entornos ubicados en esta interfaz. Siendo estos los ámbitos en los que parece más necesario la implementación de alternativas a los modelos centralizados, el proyecto que aquí se presenta parece de especial pertinencia.

Realizar un análisis y a través de este obtener una interpretación, permitirá tener los insumos necesarios para realizar una exploración proyectual que permita traer de vuelta estrategias de diseño innovadoras acordes a las características fragmentadas del territorio. La comunidad Minas esta conformada por un sistema de espacios abiertos, articulados por una infraestructura (agua entubada) que se alimenta del río Minas, la comunidad bebe de esta fuente y al mismo tiempo riega las parcelas y todas las aguas residuales acaban en un canal central que junto con el viario principal conforman una especie de filamento que da carácter a esta comunidad. Es ésta configuración hidrosocial la que le da carácter a la comunidad, y que al mismo tiempo, sugeríamos, es fuente de problemas de salud. Por lo tanto, es en este problema donde este apartado enfocará su esfuerzo.

La comunidad Minas es un campo de espacios abiertos atravesado por un viario en cuyos bordes se emplazan las viviendas en forma de un salpicado como si se tratase de un salto de rana, tienen presencia también manchas boscosas que acentúan este carácter de filamento. Se puede observar como desde el bosque nacen surcos que riegan las parcelas y conforman un mosaico lineal que desciende hacia el filamento, este mosaico esta conformado por fragmentos agrícolas, pasto, espacios residuales, huertos y viviendas que conforman este espacio hirdrosocial que relaciona la tecnología (agua entubada), sociedad (actividades agrícolas) y naturaleza (pliegues topográficos). (Ver imagen 8) 

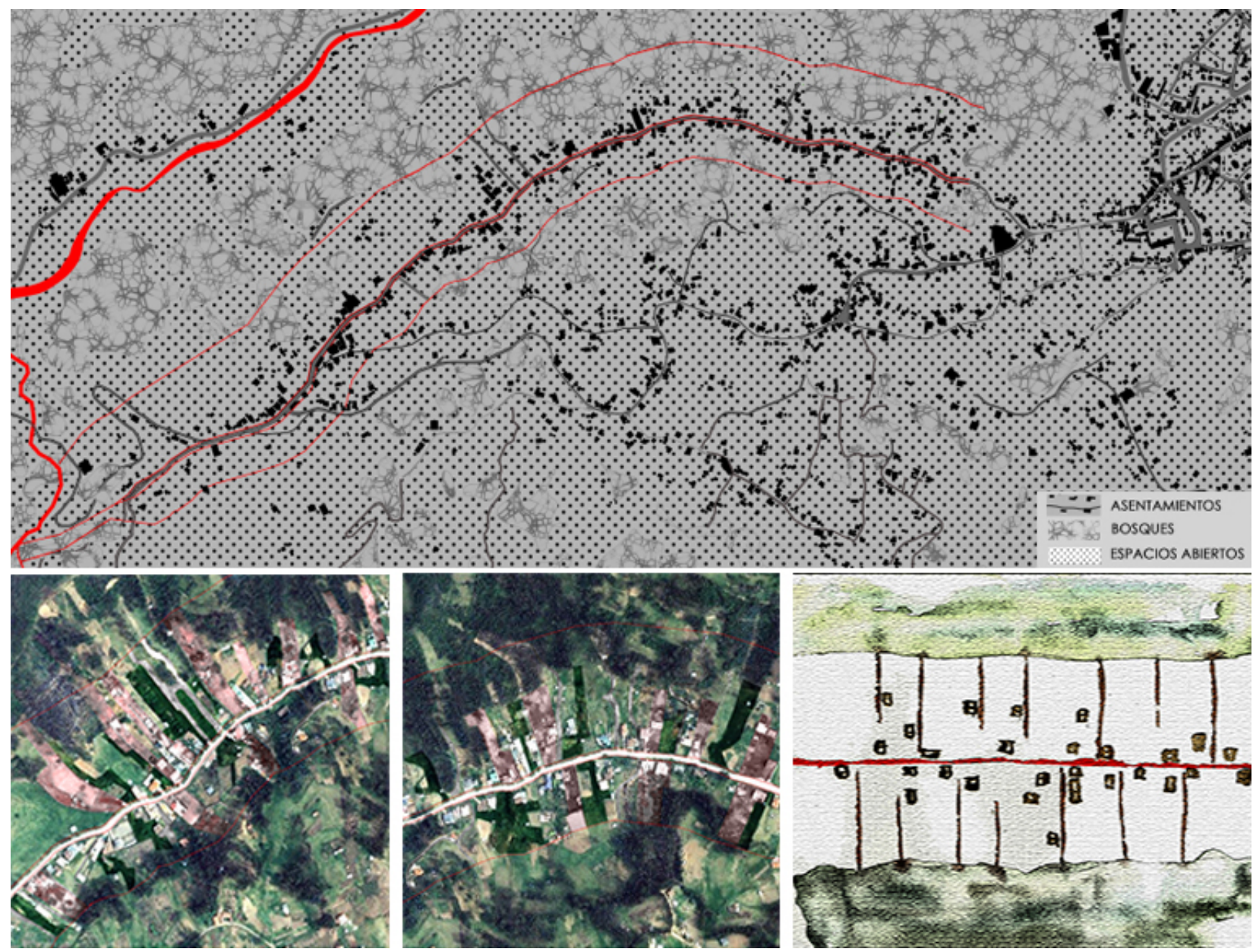

Fig. 8 Interpretación hidrosocial, comunidad Minas, elaboración propia.

\section{3.- ESTRATEGIAS}

La exploración proyectual intentará potenciar este 'filamento' que caracteriza el lugar, este filamento está constituido básicamente por la calle, para esto conceptualizaremos la calle como espacio primigenio del urbanismo, capaz de trascender de lo funcional y convertirse en un elemento protagonista. Siendo necesario recordar que la forma de entender y concebir la calle en el pensamiento moderno y el contemporáneo llevan consigo grandes diferencias. La ciudad moderna, conceptualiza el tráfico como un flujo que desde orígenes dispersos corre hacia las grandes áreas de producción y especialmente hacia el centro urbano, por lo tanto, este canal (tubo), debe tener entonces el tamaño necesario y las características físicas suficientes para asegurar este flujo, esta visión moderna privilegia lo funcional, el espacio para el automóvil. Por otro lado, para la ciudad contemporánea el problema de la movilidad ya no parece estar conceptualizados en términos de tubos, la movilidad en algunas zonas de la ciudad y el territorio, se desarrollan por filtración, como dentro de una esponja. Tubos y esponjas, es una analogía que puede ilustrar el problema contemporáneo de la movilidad, para direccionar un fluido, no necesariamente se debe recurrir a un tubo, podemos dejarlo pasar por percolación. El tubo tiene una entrada y una salida, la esponja tiene superficies de entrada y salida. La esponja es un sistema que dentro de ciertos límites se autorregula, puede conservar en su interior una cierta cantidad de fluido durante algún tiempo y luego devolverlo (Secchi, 2000). Esto lleva a replantear la idea de calle jerárquica y mono funcional por otra multifuncional que permita la permeabilidad de flujos y actividades tan variadas características de este tercer espacio.

La comunidad de Minas está conformado por fragmentos dominados por espacios abiertos, la idea de proyecto es potenciar este filamento bajo el precepto de unir espacios naturales, agrícolas y asentamientos humanos, con un profundo respeto ambiental y al mismo tiempo permitir una permeabilidad de todas las actividades presentes en este espacio. 
Finalmente es necesario repensar el sistema centralizado de tratamiento de aguas residuales que la ciudad emplea; la ciudad de Cuenca es la única ciudad en el Ecuador que da tratamiento a sus aguas residuales, esto en la planta de Ucubamba, ubicada al norte de la urbe, el $98 \%$ de sus aguas son tratadas, pero solo se considera la zona urbana, aproximadamente 8000 ha, sin embargo, si observamos que la ciudad está rodeada por una corona espumosa, difusa, que la hemos llamado 'Tercer espacio', el periurbano que se ubica en la zona de transición entre la ciudad y el campo constituye el otro $50 \%$ (9495 ha de acuerdo al PDOT 2003). En esta zona de transición el tratamiento de aguas residuales es parcial o nulo como en el caso de la comunidad de Minas, además resulta costoso y poco resiliente llevar todas las aguas a este sistema central. Parece obvio pensar que nos encontramos entonces ante nuevas oportunidades que posibilitan una mejor armonización entre crecimiento urbano y valores ambientales.

[...] Sin duda esta agua se ensuciará mas adelante; pasará sobre rocas fragmentadas y vegetales en putrefacción; diluirá tierras cenagosas y se cargará de los restos impuros vertidos por los animales y los hombres; pero aquí, en su hoya de piedra o en su cuna de juncos, es tan pura, tan luminosa, que se diría que es aire condensado [...] (Reclus \& Guazzelli, 2001)

Tradicionalmente en el recorrido del agua se podía observar una intima relación entre el hombre y la naturaleza, su flujo, su ocupación, generaban una relación natural respetando las lógicas de este recorrido y los pliegues del medio físico que lo acogía. No podemos dejar de mencionar la maravillosa descripción de este recorrido por Elisee Reclus en "Historia de un arroyo", donde va describiendo elementos significativos como la nieve, la lluvia, la tormenta; las formaciones geológicas: montañas, rocas, barrancos; el relieve del curso fluvial: el lecho tan cambiante, cascadas, remolinos, riveras; las plantas: juncos cañas y carrizos; también los animales que recorren las orillas: peces multicolores, libélulas y mosquitos. Además Reclus, como geógrafo humano piensa en la utilidad, en el servicio que nos brinda el arroyo, en la pesca y riego para cultivos y jardines; en los molinos y fábricas que va encontrando aguas abajo; en el agua de las ciudades que obliga a construir represas. Es necesario dice, aprender a utilizarla de una manera completa para la irrigación de nuestros campos y la dinamización de nuestras riquezas, entonces podremos hacerla trabajar para el servicio común de la humanidad, en lugar de dejar que asole los cultivos y se extravíe en pantanos pestilentes (Reclus \& Guazzelli, 2001). Sin embargo, esta relación entre el hombre y los procesos naturales, basados en el entendimiento profundo de los complejos y dinámicos procesos ecológicos, se han visto afectados en los tiempos modernos, la idea de control y centralización, soterró estos procesos mediante un sistema de infraestructuras invisibles, teniendo como consecuencia una desconexión entre el recorrido del agua y los procesos ecológicos del paisaje (Stokman, 2008). Por lo tanto, este apartado intenta introducir el manejo del agua como parte integral del paisaje urbano, en un espacio como hemos visto, está dominado por los espacios abiertos y una clara vocación agrícola.

Proporcionar agua limpia y un adecuado sistema de saneamiento no es exactamente ciencia espacial, las tecnologías básicas y los principios de ingeniería son conocidos y dominados, los sistemas de gestión son entendidos, los procesos biológicos, físicos y químicos están bien comprendidos; sin embargo, llama la atención que mas de mil millones de personas en el mundo aún sufran de un inadecuado (tanto en cantidad como en calidad) acceso al agua limpia y casi dos mil millones de un insatisfactorio tratamiento de aguas residuales, siendo posible afirmar que las enfermedades relacionadas con el agua son la principal causa de muertes prematuras en los países en desarrollo (Swyngedouw, 2006b). Este problema se agrava en los denominados países en vías de desarrollo y Ecuador no es la excepción, por tal motivo, este proyecto de investigación esta enfocado en explorar estrategias innovadoras que permita un cambio de paradigma en el manejo del recurso agua, particularmente en lo que respecta a aguas residuales, que permitan una optimización y mayor acceso a este recurso.

En la búsqueda de una solución a la contaminación de las fuentes de agua y de los suelos por las descargas de las aguas residuales residenciales, este trabajo plantea la exploración de un sistema hidráulico de saneamiento desconectado de la red central que se encuentra al otro extremo de la ciudad, este sistema consiste en el diseño de un sistema de humedales artificiales para el tratamiento de aguas residuales producto de las descargas directas a las quebradas y canales por parte de los habitantes de esta comunidad. Esta tecnología de humedales artificiales aprovecha los procesos físico, químicos y biológicos que se presentan al interactuar entre sí el agua, el medio filtrante, las plantas, los microorganismos y la atmósfera. Este proceso se lleva a cabo a través de la remoción de sólidos suspendidos por sedimentación y filtración, a la biodegradación de la materia orgánica a partir de microorganismos aeróbicos y anaeróbicos y a la eliminación de microorganismos patógenos por sedimentación, filtración y la acción depredadora de otros organismos (Arias Martínez, Betancur Toro, Gómez Rojas, Salazar Giraldo, \& Hernández Ángel, 2010). Esta técnica de fitorremediación se 
caracteriza por ser una práctica de limpieza pasiva y estéticamente agradable que aprovecha la capacidad de las plantas y la energía solar para el tratamiento de estas aguas contaminadas. En esta técnica las plantas actúan como trampas o filtros biológicos que descomponen los contaminantes y estabilizan las sustancias metálicas presentes en el suelo y agua al fijarlos en su raíces y tallos, o metabolizándolos tal como lo hacen los microorganismos para finalmente convertirlos en compuestos menos peligrosos.

Para el caso de estudio, la técnica propuesta es el diseño de un humedal artificial de flujo subsuperficial, este sistema consiste en un filtro biológico relleno de un medio poroso (piedra volcánica, grava), en el cual las plantas macrófitas se siembran en la superficie del lecho filtrante y las aguas residuales pretratadas atraviesan de forma horizontal el lecho filtrante, en este sistema el nivel del agua se mantiene por debajo de la superficie del medio granular, por tanto, la presencia de plagas es mínima al igual que la ausencia de malos olores, además su condición modular permite adicionar nuevas unidades de acuerdo a las necesidades y constituye una solución económicamente viable.



Fig. 9. Sistema hidráulico de saneamiento fuera de red, elaboración propia

\section{4.- CONCLUSIONES}

Considerando que el estudio esta en fase inicial la discusión y resultados son tentativos y no conclusivos.

La parroquia Baños tiene como su valor mas preciado la presencia de páramos en gran parte de su territorio , los páramos como lo habíamos visto son ecosistemas de gran riqueza ecológica y, a su vez, juegan un importante papel en la economía de sociedades andinas (Díaz, Navarrete, \& Suárez, 2005), por lo tanto, su preservación y manejo sostenible es fundamental para garantizar la disponibilidad presente y futura de abastecimiento de agua en estas comunidades. La presencia de cultivos, la ganadería, la deforestación, la construcción indiscriminada de viario, así como otras actividades antrópicas se presentan como principal amenaza que podría modificar el delicado equilibrio de este ecosistema. Si sumamos a esto estudios que estiman un aumento de 2 a 4 grados centígrados para fines de siglo, es posible que su especial vegetación no pueda adaptarse a estas temperaturas (De Meulder, Shannon, \& Rojas, 2015);por tanto, cualquier intervención debe estar bajo el precepto de su protección y mantenimiento. 
La construcción de humedales artificiales constituye una alternativa costo - efectiva interesante, ambientalmente amigables y que pueden aplicarse en estos territorios, frente al tratamiento convencional particularmente en países en desarrollo (Gopal, 1999), teniendo como una de las consideraciones mas importantes su relativo bajo precio en la construcción, operación y mantenimiento, frente al sistema de tratamiento convencional. La construcción y mantenimiento de un sistema convencional de agua residuales a mas de ser muy costoso necesita de un período largo de amortización que puede ser de entre 50 y 100 años, tiempo, con el que este espacio de transición no cuenta, debido al acelerado proceso de transformación y crecimiento de estos territorios. Por lo tanto, es necesario repensar de manera urgente estos conceptos de saneamiento con un nuevo enfoque que interrelacione la construcción de infraestructuras, funciones ecológicas y espacios libres para la gente, como camino posible de nuevos sistemas urbanos sostenibles (Stokman, 2008).

Al igual que muchas ciudades Latinoamericanas, una de las prioridades para Cuenca - Ecuador es reducir la pobreza y mejorar la calidad de vida de sus habitantes, gobiernos estatales y locales insisten en focalizaron sus esfuerzos en dos perspectivas, por un lado la reducción de pobreza rural y por otro la pobreza urbana, superar esta dicotomía solo será posible cuando se entienda esta dualidad Rural Urbana como complementarias y parte de un mismo territorio. Por lo tanto la exploración de un sistema de tratamiento de aguas fuera de red, no solo favorece el carácter productivo de un sistema de espacios abiertos agrícolas, sino también podría promover una autosuficiencia alimentaria, fomentar la economía rural, y algo muy importante una aproximación geográfica entre producción y consumo que ya, a finales del siglo XIX, los geógrafos anarquistas (Reclus y Kropotkin) miraron como capital y ahora la ecología contemporánea ve como absolutamente esencial para el ahorro energético y la disminución de los gases de efecto invernadero (Oyon, 2011). Por lo tanto, reducir esta dependencia del centro, fortaleciendo estas nuevas centralidades puede ser una vía para la forma de entender y concebir la nueva ciudad contemporánea, la "ciudad - territorio".

\section{BIBLIOGRAFÍA:}

Amado, M., \& Poggi, F. (2014). Solar energy integration in urban planning: GUUD model. Energy Procedia, 50, 277-284. https://doi.org/10.1016/j.egypro.2014.06.034

Arias Martínez, S. A., Betancur Toro, F. M., Gómez Rojas, G., Salazar Giraldo, J. P., \& Hernández Ángel, M. L. (2010). Fitorremediación con humedales artificiales para el tratamiento de aguas residuales porcinas. Informador Técnico (Colombia), 74, 12-22.

Avila Sánchez, H. (2001). Ideas y planteamientos teóricos sobre los territorios periurbanos: Las relaciones campo-ciudad en algunos países de Europa y América. Investigaciones Geográficas, 45, 108-127.

Ballet, C. Llop, J. M. (2004). Miradas a otros espacios urbanos: Las ciudades intermedias ., VIII, 113(108), 1-13.

Banco Interamericano de Desarrollo. (2014). Cuenca ciudad sostenible / Plan de acción. Bid.

Boelens, R., Hoogesteger, J., Swyngedouw, E., Vos, J., \& Wester, P. (2016). Hydrosocial territories: a political ecology perspective. Water International, 41(1), 1-14. https://doi.org/10.1080/02508060.2016.1134898

Bonfiglio, G. (2002). Servicios de agua en zonas periurbanas de Lima Metropolitana. La experiencia del proyecto Alimentacio_n de Agua para Pueblos Jo_venes (APPJ). Lima: Banco Mundial e Programa de Agua y Saneamiento.

Burbano, D., Di Campli, A., Rodriguez, N., \& Solórzano, M. (2017). Transiciones Territoriales : reflexiones teóricas tras un concepto.

Choguill, C. L. (1999). Community infrastructure for low-income cities: The potential for progressive improvement. Habitat International, 23(2), 289-301. https://doi.org/10.1016/S0197-3975(98)00053-8

Corboz, A., \& Marot, S. (2001). Le Territoire comme palimpseste et autres essais. Besançon : Ed. de l'Imprimeur. Retrieved from http://cataleg.upc.edu/record=b1208803 S1* cat

Criqui, L. (2015). Infrastructure urbanism: Roadmaps for servicing unplanned urbanisation in emerging cities. Habitat International, 47, 93-102. https://doi.org/10.1016/j.habitatint.2015.01.015

De Meulder, B., Shannon, K., \& Rojas, C. (2015). Water urbanism in Bogota. Exploring the potentials of an interplay between settlement patterns and water management. Habitat International. 
https://doi.org/http://dx.doi.org/10.1016/j.habitatint.2015.03.017

Díaz, M., Navarrete, J., \& Suárez, T. (2005). Páramos: Hidrosistemas Sensibles. Revista de Ingeniería, 22, 64-75.

Ferrer-Martí, L., Garwood, A., Chiroque, J., Escobar, R., Coello, J., \& Castro, M. (2010). A Community Small-Scale Wind Generation Project in Peru. Wind Eng, 34, 277-288.

Gopal, B. (1999). Natural and constructed wetlands for wastewater treatement: Potentials and problems. Water Science and Technology, 40(3), 27-35. https://doi.org/10.1017/CBO9781107415324.004

Groh, S., Van der straeten, J., Edlefsen lasch, B., Gershenson, D., Leal filho, W., \& Kammen, D. (2015). Decentralized Solutions for Developing Economies. Springer, Zurich, 1st. Ed.

Muñiz, I., \& García, M. A. (2006). SPRAWL. Definición, causas y efectos.

Oyon, J. L. (2011). Disperción frente a compacidad.pdf.

Reclus, É., \& Guazzelli, E. (2001). El Arroyo. Valencia : Media Vaca.

Rhoades, R. (2006). Development with identity: Community, culture and sustainability in the Andes, Development with Identity: Community, Culture and Sustainability in the Andes.

Rifkin, J. (2014). The Zero Marginal Cost Society: The Internet of Things, the Collaborative Commons, and the Eclipse of Capitalism. New York: Palgrave Macmillan.

Secchi, B. (2000). Prima lezione di urbanistica. Roma : Laterza. Retrieved from http://cataleg.upc.edu/record=b1195603 S1*cat

Secchi, B. (2013). La città di ricca città dei poveri. Roma - BAri: Laterza \& Figli.

SENPLADES. (2013). Plan Nacional del Buen Vivir.

Silver, J. (2014). Incremental infrastructures: material improvisation and social collaboration across postcolonial Accra. Urban Geography.

Stokman, A. (2008). Water Purificative Landscapes - Constructed Ecologies and Contemporary Urbanism.

Swyngedouw, E. (2006a). Circulations and metabolisms : ( Hybrid ) Natures and ( Cyborg ) cities, (March 2013), 37-41.

Swyngedouw, E. (2006b). Human Development Report 2006 Human Development Report Office Power , Water and Money: Exploring the Nexus. Human Development, (April).

UN-HABIT. (2015). Issue Papers and Policy Units of the Habitat lii Conference, (April).

Yadoo, A., \& Cruickshank, H. (2012). The role for low carbon electrification technologies in poverty reduction and climate change strategies: A focus on renewable energy mini- grids with case studies in Nepal, Peru and Kenya. Energy Police, 42, 591-602. 